\title{
AS POLÍTICAS DE ACESSO A INOVAÇÃO NO BRASIL: O PROGRAMA ALI
}

\author{
ARAUJO, Geraldo Jose Ferraresi de ${ }^{1}$
}

\begin{abstract}
RESUMO: A inovação é um instrumento de geração de vantagem competitiva. No Brasil, o governo federal realizou uma série de políticas com o objetivo de ampliar a competitividade das empresas brasileiras através da inovação, sendo uma dessas o Programa Agentes Locais de Inovação (ALI). Logo, a proposta desse artigo é analisar as políticas públicas de acesso à inovação no Brasil, com destaque para o Programa ALI, seus objetivos e sua importância para edificação de vantagem competitiva tanto nas micro quanto nas pequenas empresas. A metodologia utilizada foi à pesquisa qualitativa bibliográfica documental indireta. O ALI vem ao encontro tanto das necessidades das micro e pequenas empresas quanto do estado brasileiro, pois cria e amplia a capacidade dessas organizações de acessar e gerar conhecimento, para produzir inovação e tecnologia que amplie a competitividade dos negócios para acompanhar a globalização além de contribuir no salto competitivo do Brasil.
\end{abstract}

Palavras-Chave: Politicas públicas. Inovação. Programa Agentes Locais de Inovação.

SUMMARY: Innovation is a tool to generate competitive advantage. In Brazil, the federal Government carried out a series of policies aiming to increase the competitiveness of Brazilian companies through innovation, being one of those Local Agents of Innovation Program (ALI). Therefore, the proposal of this article is to analyze public policies of access to innovation in Brazil, with emphasis on the Program ALI, your goals and your importance to building competitive advantage both on micro and small enterprises. The methodology used was the qualitative research document bibliographic hint. ALI comes to meet both the needs of micro and small enterprises as the State as it creates and enlarges the capacity of these organizations to access and generate knowledge, to produce innovation and technology that extend the competitiveness of business to accompany globalization in addition to contributing in competitive jump Brazil.

Keywords: Public Policy. Innovation. Local Innovation Agents Program.

\section{INTRODUÇÃO}

Segundo Castells (2002) a globalização é a integração mais estreita dos países e dos povos que resultou da enorme redução dos custos de transportes e de comunicação e a destruição de barreiras artificiais à circulação de mercadorias, serviços, capitais, conhecimentos e pessoas, como consequência desse processo é a crescente interligação e interdependência entre estados, organizações e indivíduos do mundo inteiro, nas relações econômicas, sociais e políticas. Especificamente no que se refere às empresas são a ampliação da concorrência; mercados consumidores e fornecedores; integração das cadeias produtivas e dos mercados financeiros em escala mundial.

A globalização também é percebida através da aplicação de conhecimento na geração de novos conhecimentos e dispositivos, num contínuo de inovação, uso e processamento da informação. Em tal quadro, a competitividade de empresas e nações esta cada vez mais relacionada à sua capacidade inovativa. Logo, os estados nacionais que se pretendem competitivos devem contemplar em suas políticas 
públicas medidas que tornem suas respectivas empresas diferenciadas nos mercados internacionais, sendo uma dessas políticas o acesso à inovação. (CASTELLS, 1999)

Para Schumpeter (1984) a inovação constitui se no fator central do crescimento econômico, tendo nas empresas os agentes principais destas transformações. O comportamento das empresas é determinante para a ocorrência de mudanças tecnológicas, na medida em que são consideradas instituições de produção, de negócios e de aprendizado.

No Brasil, país onde historicamente a empresa nacional não foi protagonista no processo de pesquisa, desenvolvimento e inovação; o desenvolvimento tecnológico não acompanhou o processo de industrialização, e aliado a sua condição periférica na divisão internacional de trabalho, com características de baixo crescimento econômico, graves problemas sociais, exportador matérias-primas de baixo valor agregado que não demandam grande aporte de conhecimento ou tecnologia e importador de produtos industrializados com maior valor agregado (DAGNINO, 2004), a inovação tem importância estratégica para que a criação e sustentação de vantagem competitiva para as empresa brasileiras possam fazer frente não somente a concorrência nos mercados nacionais, como também ganhar espaço nos principais mercados globais.

Porém, dado a situação de atraso tecnológico das empresas, falta de competitividade, problemas macro conjunturais de natureza econômica, social, política e de infraestrutura, o governo brasileiro, sobretudo a partir da primeira década do século XXI vem elaborando uma série de políticas públicas com o objetivo de fomentar a inovação, não somente com o objetivo de ampliar a competitividade das empresas nos mercados globalizados através da inovação, mas também poder sustentar de acordo com a Teoria da Eficiência Schumpteriana (BAPTISTA, 2007), crescimentos econômicos em longo prazo e consequentemente superar a sua condição de periferia na divisão internacional de trabalho.

Logo o objetivo geral desse artigo é analisar o Programa Agente Locais de Inovação, uma parceria entre o Serviço Brasileiro de Apoio a Micro e Pequena Empresa - SEBRAE e o Conselho Nacional de Desenvolvimento Cientifico e Tecnológico - CNPq, seus objetivos e sua importância para edificação de vantagem competitiva tanto nas micro e pequenas empresas quanto para o Brasil. Como objetivo especifico descrever sobre a inovação e sua importância para o desenvolvimento econômico e competitivo das nações, o histórico das políticas públicas de acesso à inovação no Brasil, sistema nacional de inovação brasileiro com foco nas seguintes instituições: as micro e pequena empresas, SEBRAE, SEBRAE SP e o CNPq, por onde também o artigo esta delimitado.

\section{METODOLOGIA}

No que se refere a sua natureza da metodologia, foi utilizada a ferramenta qualitativa, de cunho exploratório bibliográfico. Para tanto, foi realizado levantamento bibliográfico nas bases dados: Scientific Electronic Library Online; Web of Science; Instituto de Pesquisa Econômica Aplicada, Universidade Corporativa SEBRAE, artigos da Revista Brasileira de Inovação e Revista de Administração da Universidade de São Paulo, Biblioteca de Teses e Dissertações da Universidade Estadual Paulista e da Universidade Estadual de Campinas e o sitio eletrônico do Conselho Nacional de Desenvolvimento Cientifico e Tecnológico.

Essas fontes foram consultadas nessas bases de dados foram cruzadas as seguintes palavraschaves: politicas públicas, inovação, Programa Agentes Locais de Inovação, micro e pequenas empresas, sistema nacional de inovação, economia da inovação, globalização, SEBRAE, SEBRAE-SP, CNPq, vantagem competitiva. 
Portanto, a pesquisa científica do presente artigo contemplou o método histórico dedutivo de natureza qualitativa exploratória, construída através do levantamento bibliográfico.

\section{REVISÃO DA LITERATURA}

\subsection{Políticas Públicas, inovação e desenvolvimento econômico}

Para Teixeira (2002) políticas públicas são diretrizes, princípios norteadores de ação do poder público; regras e procedimentos para as relações entre poder público e sociedade, mediações entre atores da sociedade e do Estado. São, nesse caso, políticas explicitadas, sistematizadas ou formuladas em leis, programas e linhas de financiamentos que orientam ações que normalmente envolvem aplicações de recursos públicos.

Especificamente no que se refere a seu caráter estratégico, ligadas diretamente aos modelos de desenvolvimento econômico, segurança nacional e política industrial e à constituição de fundos públicos, devem ser considerados o progresso científico, inovações tecnológicas, estrutura produtiva do país e os seus desdobramentos nos macro cenários sociais, políticos e econômicos.

Foi durante a $2^{\mathrm{a}}$ Guerra Mundial que se criou a relação entre ciência e política. A percepção de sua importância materializou fontes de financiamento governamentais para cientistas e engenheiros no pósguerra, para pesquisa e desenvolvimento no setor cientifico, tecnológico, militar e industrial.

No que se tange particularmente a política industrial, foi o sucesso dessa política pública estratégica no Japão, que desencadeou a reformulação dos antigos modelos de política industrial e científico-tecnológica dos países desenvolvidos (BRAUN, 2006). Segundo o autor, o modelo japonês acabou orientando as novas formas organização das políticas de ciência e tecnologia, baseado em três princípios centrais:

- Identificação de áreas tecnológicas consideradas chave;

- Participação ativa do governo como agente intermediador;

- Desenvolvimento de projetos de pesquisa de forma colaborativa entre indústria e academia.

As relações colaborativas foram decisivas para o desenvolvimento das políticas entre empresas, universidades e institutos de pesquisa, que tornaram mais sensíveis às demandas do setor produtivo, o que gerou significativas mudanças nas relações entre ciência e tecnologia e sociedade (M. OLIVEIRA, 2014).

Neste contexto, a emergência e adoção do conceito de Sistema Nacional de Inovação - SNI têm influenciado consideravelmente as políticas públicas de acesso à inovação em um primeiro momento nos países desenvolvidos e posteriormente nos países subdesenvolvidos.

Dado a natureza sistêmica da inovação, a importância da interação e integração de diferentes instituições e recursos foi valorizada, porém o protagonismo deixou de ser o complexo científico e tecnológico; universidades, institutos de pesquisa de ciência e tecnologia; e passou a ser a empresa.

Para Pereira e Dathein (2012) a empresa caracteriza-se como o agente central da inovação, desempenhando papel fundamental na dinâmica econômica capitalistas.

A empresa é uma instituição dotada de capacidade de acumulação de conhecimento (PENROSE, 2006), o qual vem sendo tratado como o principal insumo produtivo, responsável pelas constantes inovações. Por sua vez, em grande medida as inovações têm sido resultado da trajetória evolutiva empresarial, que é condicionada pelo processo de aprendizado desenvolvido nos ambientes interno e interativo em que a empresa atua. 
De acordo com Braun (2006) o desenvolvimento tecnológico realizado pelas empresas passou a ser visto como uma variável chave nos modelos de crescimento econômico, sendo o conhecimento um dos fatores de produção e do desenvolvimento de novos produtos como o principal motor do crescimento econômico, a racionalidade passou a ser de que os governos devem apoiar atividades ligadas à inovação e geração de conhecimento (KALLERUD, 2010), na medida em que Averch (1985) aponta que os que que os ganhos sociais com essas atividades excediam em muito os privados.

De acordo com os seus defensores, a inovação apresenta uma relação direta com as exportações, com o ritmo de crescimento das empresas, com a melhora do valor agregado da produção nacional e com a estrutura salarial (SALERMO; KUBOTA, 2008).

Averch (1985) afirma que, a partir de meados da década de 1970, o Conselho Econômico da Presidência dos Estados Unidos passou a perceber a inovação tecnológica como uma condição necessária para aumentar a taxa de crescimento econômico no longo prazo. Todavia, a leitura era de que em muitos casos as empresas não eram capazes de perceber, em sua totalidade, os benefícios a serem alcançados a partir do desenvolvimento tecnológico.

A Economia da Inovação de acordo com Organization For Economic Co operation Development (1997) define que o desenvolvimento econômico é conduzido pela inovação por meio de um processo dinâmico em que as novas tecnologias substituem as antigas, um processo por ele denominado "destruição criadora". A inovação é observada como experimento de mercado e a procura mudanças amplas e extensivas que reestruturam fundamentalmente indústrias e mercados.

A Economia da Inovação rejeita a visão linear do processo inovativo, ressaltando o fato de que ele se trata na realidade de um processo dinâmico e interativo entre pesquisa, tecnologias existentes, difusão de conhecimento e mercado. Sendo assim, cabe às políticas públicas atuar em termos de facilitar a adaptação das empresas a esse ambiente (BRAUN, 2006).

Para Calmanovici (2011) a política industrial então deve ser articulada com as macro políticas, principalmente com a política monetária e fiscal. De pouco adiantam esforços para desenvolver a atividade inovadora, se variáveis chaves da economia como o câmbio, juros e impostos não estiverem alinhados com uma estratégia de desenvolvimento via inovação.

Em suma, há uma correlação substancial entre inovação, geração de renda, inserção internacional, demanda efetiva e desenvolvimento. As políticas públicas de acesso à inovação devem estar atreladas a uma estratégia coerente de política industrial. Para Gadelha (2001), a política industrial seria foco de intervenção pública na dinâmica de inovação da indústria visando promover o desenvolvimento das economias nacionais.

\subsection{As Políticas Públicas de acesso a inovação no Brasil: uma perspectiva histórica}

\subsubsection{Evolucão das políticas de ciência, tecnologia, inovacão e desenvolvimento econômico}

O desenvolvimento da ciência e tecnologia no Brasil foi moldado por uma complexa interação entre forças econômicas e regimes políticos. Durante a fase colonial até o século XX, o país foi uma plataforma de exportações de produtos primários, tanto agrícolas quanto de minérios, para o mundo. A história econômica brasileira foi caracterizada nesse período por uma sucessão de ciclos de exportações de produtos como o açúcar, ouro, algodão, cacau, borracha e café. A importância desses produtos continuou no século seguinte, o que ofereceu as fundações para o início da industrialização brasileira. 
É possível caracterizar o esforço brasileiro de industrialização desde a $2^{\mathrm{a}}$ Guerra Mundial em três diferentes fases. A primeira fase, que se estendeu desde o pós-guerra até de 1980, pode ser caracterizada como a fase da busca do desenvolvimento por intermédio do crescimento ou da industrialização extensiva. A segunda fase, que correspondente às duas últimas décadas do século $\mathrm{XX}$, marcada pela busca da eficiência, por meio de políticas econômicas liberais, como a forma de assegurar o desenvolvimento brasileiro (VIOTTI, 2008).

Para Saviani (2007) na fase atual, no inicio do século XXI, o país buscou um novo modelo de desenvolvimento, de revalorização das políticas públicas como ferramenta necessária ao desenvolvimento, mas não há uma ruptura com a valorização dos mecanismos de mercado como instrumentos do desenvolvimento. Mas um de seus aspectos é a relevância que vem assumindo a inovação no discurso da política de ciência e tecnologia e, poderia vir a constituir a base de uma nova política de desenvolvimento.

\subsubsection{Desenvolvimento via crescimento}

O Brasil é um país de industrialização tardia, a mesma só vai ganhar expressão econômica na segunda metade do século XX. Para Bagattolli (2013) o período que vai de 1950 ao de 1980 foi marcado pelo processo de industrialização via substituição de importações. O Estado protegeu a indústria através de praticas protecionistas, apoiou investimentos privados nacionais e estrangeiros, assim como criou empresas públicas em setores estratégicos para o desenvolvimento nacional. A principal inspiração teórica e doutrinária para essa atuação foi a escola de pensamento econômico desenvolvido pela Cepal. Por considerar a indústria como fonte de dinamismo econômico, os cepalinos defendiam a adoção de uma política massiva de industrialização como forma de alcançar uma melhoria na qualidade de vida da população.

Para executar o programa de industrialização por substituição de importações e ter acesso à tecnologia necessária para o desenvolvimento do país, a estratégia adotada foi de atração de investimento estrangeiro, com ênfase na instalação de subsidiárias locais de empresas transnacionais. Essa percepção da forma como se daria a absorção e a geração do progresso técnico associado ao processo de industrialização por substituição de importações constitui o que pode ser chamado de política de C\&T implícita. Essa política era composta por dois elementos. O primeiro, entendido como a promoção da progressiva absorção das capacidades de produção de bens manufaturados. O segundo elemento na expectativa de que a industrialização iria trazer o processo de mudança técnica (DAGNINO, 2007).

A integração das empresas transnacionais na estrutura produtiva nacional levou de fato a um aumento no grau de complexidade da industrialização. Todavia, este processo não só manteve os laços de dependência tecnológica da indústria local com os fornecedores de tecnologia dos países avançados como acabou reforçando-os (SAGASTI, 1986). Empresas estrangeiras foram atraídas para explorar o mercado interno brasileiro, e não para que se tornassem bases de exportação, ou para que desenvolvessem, no Brasil, novos produtos. A pesquisa, o desenvolvimento e parte substancial da engenharia localizavam-se no exterior. $\mathrm{O}$ uso de tecnologia externa ao longo do processo de industrialização foi marcante, o que acabou inibindo a necessidade de geração conhecimento científico-tecnológico dentro do Brasil.

Para Dagnino (2007) o resultado do primeiro elemento da política de C\&T implícita no modelo de desenvolvimento via crescimento alavancado pela industrialização, a absorção da capacidade tecnológica de produção de bens manufaturados foi um sucesso. Contudo, o segundo elemento industrialização do processo de mudança técnica não logrou êxito. 
Sicsú e Castelar (2009) afirmam que a combinação de proteção excessiva, desarticulação entre a oferta de conhecimento e o processo produtivo, base produtiva dominada em setores-chave por multinacionais inibiram políticas de incentivo à inovação que engendraram o setor produtivo com baixa produtividade, de padrão de qualidade inferior ao internacional, pouco competitivo frente aos produtos e processos similares produzidos internacionalmente.

\subsubsection{Desenvolvimento via eficiência}

As duas ultimas décadas do século XX foram marcados por fatores conjunturais herdados da fase de desenvolvimento anterior: alta inflação, dívida externa crescente, abertura comercial e criação do MERCOSUL. Para Pacheco e Corder (2011) a segunda fase do desenvolvimento brasileiro período que corresponde às últimas duas décadas do século $\mathrm{XX}$, foi caracterizado pelo processo de progressiva liberalização da economia, através de programas de privatização; desregulamentação; redução ou remoção de subsídios e barreiras tarifárias ao comércio internacional, câmbio flutuante e livre movimentação de capitais estrangeiros.

De acordo com Cassiolato e Lastres (2007) julgava-se que com a abertura do mercado doméstico para produtos, serviços e capitais estrangeiro, estabilização das variáveis macroeconômicas seria suficiente para o desenvolvimento industrial do país e a criação de inovações tecnológicas que seriam incorporadas aos produtos brasileiros com a finalidade de agregar valor, ou seja, as empresas nacionais seriam compelidas a inovar e facilitar o processo de transferência de tecnologias estrangeiras para o país em decorrência da sua maior exposição frente à concorrência internacional, aumentando assim a demanda de conhecimentos do complexo científico local.

Um balanço do final do período indica que as consequiências das políticas adotadas nas décadas de 1980 e 1990 foram muito aquém do que se esperava. Embora a produção científica, expandiu-se a taxas elevadas, a inovação não evoluiu.

Para Villaschi (2005) as mudanças nas estruturas institucionais e econômicas do Brasil no final do século XX não levaram em conta a dinâmica das modificações no cenário científico, tecnológico e econômico internacional. Além disso, embora a economia tenha superado o problema da instabilidade de preços, o compromisso político com o déficit público tem implicado corte nos gastos em áreas cruciais para a inovação.

Em síntese, a abertura ocorreu, mas o crescimento da economia até o final do período foi baixa. A brutal elevação das pressões competitivas, a abertura para os investimentos estrangeiros não demonstrou capacidade efetiva de estimulo a inovação para as empresas brasileiras.

\subsubsection{Desenvolvimento via inovação}

A terceira fase do desenvolvimento brasileiro inicia-se na virada do século XXI. O país busca um novo tipo de desenvolvimento, uma combinação de política econômica conservadora com política social progressista. A adoção de políticas ativas para promover a inovação passou a assumir importância no debate sobre as políticas econômicas, industriais e de C\&T (VILHA, 2013).

Os principais marcos regulatórios estão na Política Industrial, Tecnológica e de Comércio Exterior (PITCE), instituída em 2003, na Lei da Inovação (2004), na Lei do Bem (2005), no Programa de 
Crescimento Acelerado em CT\&I (PAC DA CIÊNCIA, 2007), na Política de Desenvolvimento Produtivo (2008) e no Programa Brasil Maior (2011) e com destaque para Estratégia Nacional de Ciência, Tecnologia e Inovação - ENCTI (2011). Em comum, neste conjunto de políticas e leis, está o reconhecimento da importância da inovação para o desenvolvimento econômico e da necessidade de atuação política visando aprimorar quantitativa e qualitativamente o sistema de inovação do país.

Para o Ministério da Ciência, Tecnologia e Inovação [MCTI] (2012) a ENCTI dá continuidade e aprofunda as orientações dos planos anteriores, tendo os seguintes eixos orientadores: consolidar, aperfeiçoar e modernizar o Sistema Nacional de Ciência, Tecnologia e Inovação, expandindo a base científica e tecnológica nacional; promoção da inovação nas empresas; novo padrão de financiamento público para o desenvolvimento científico e tecnológico; fortalecimento da pesquisa e da infraestrutura científica e tecnológica e formação e capacitação de recursos humanos.

O documento que formaliza a ENCTI parte da identificação das principais tendências das políticas nacionais de ciência, tecnologia e inovação $(C, T \& I)$ e em todo o mundo como forma de contextualizar a política nacional. $\mathrm{O}$ fortalecimento da inovação empresarial com vistas ao aumento da competitividade industrial continua a ser um objetivo comum, especialmente em termos da elevação da produtividade, do crescimento do emprego e da melhoria da qualidade de vida (MCTI, 2012).

A inovação esta assumindo papel mais relevante na política de desenvolvimento científico e tecnológico do país, como propõe a abordagem associada ao Sistema Nacional de Inovação.

\subsection{Sistema Nacional de Inovação, atores ea realizadade brasileira}

Para Possas (2008) os sistemas de inovação, conceito neo-schumpeteriano, foi elaborado por cientistas sociais em busca de explicações para as variações nos graus de competitividade das diferentes economias e, acima de tudo, em relação à capacidade de inovar dessas economias frente à importância crescente dos mercados internacionais. Observou-se que as distintas culturas de inovação influenciam de forma crítica a capacidade dos atores econômicos e dos formuladores de políticas de produzir e apoiar a inovação.

Com base nisso, segundo Perez (2001), o Estado desempenha papel fundamental no processo de aglutinação de interesses e incentivos à promoção das inovações, além de ter capacidade própria de promover inovações por meio de empresas e órgãos públicos (universidades e laboratórios de pesquisa). Um SNI reflete, em grande medida, a forma como o Estado estabelece políticas, definindo prioridades ao longo do tempo, e se utiliza das condições favoráveis dos mercados (em âmbitos nacional e internacional) como um recurso indispensável à promoção do desempenho econômico. As inovações organizacionais e institucionais são moldadas a partir dessa complexa e intrincadas relação e acabaram por refletir a posição das diferentes economias nacionais em função de sua dotação de recursos (NELSON, 2006).

Para Malerba (2003) o desempenho de um Sistema Nacional de Inovação está relacionado ao seu processo evolucionário, cuja trajetória compreende aspectos relativos ao conhecimento, à tecnologia e aos atores: empresas e suas redes de cooperação e interação; universidades e institutos de pesquisa; instituições de ensino; sistema financeiro; sistemas legais e instituições de coordenação (PEREITA; DATHEIN, 2012).

Assim, o SNI passou a ser entendido como suporte fundamental para a promoção do desenvolvimento econômico, pois compreende um conjunto de atores e instituições cuja trajetória interativa tem sido fundamental para o desempenho das economias industrializadas, em uma perspectiva histórica (PEREITA; DATHEIN, 2012). 
Porém, no que se refere ao Sistema Nacional de Inovação brasileiro, Albuquerque (1998) afirma que o mesmo, ainda, não esta consolidado, dado: desarticulação entre as políticas de ciência, tecnologia e inovação com políticas de desenvolvimento econômico; precária infraestrutura cientifica; industrialização atrelada ao capital externo; dependência da tecnologia estrangeira; falta de articulação entre os atores institucionais, sobretudo entre o setor público e o privado; baixa produtividade empresarial; desarticulação entre as instituições de pesquisa e o setor produtivo; elevada inflação na década de 80 e o alto déficit público.

Identificam-se, dessa maneira, duas grandes vertentes que englobam os principais desafios institucionais identificados. A primeira diz respeito à convergência e à integração entre as políticas públicas de apoio à competitividade e as ações e programas especificamente focados em CT\&I. A segunda agrega aspectos referentes à necessidade de interseção de esforços institucionais de promoção da inovação empreendidos pelo setor público, pelo setor privado e pelas instâncias de pesquisa e desenvolvimento.

Em suma, a formulação de políticas a partir do conceito de Sistemas Nacionais de Inovação enfatiza a importância de pensá-las de forma integrada e coesa. A fraqueza do sistema de inovação no Brasil constitui-se um dos maiores entraves ao processo de superação do subdesenvolvimento brasileiro e sua condição periférica na divisão internacional de trabalho.

Dentro do Sistema Nacional de Inovação brasileiro, especificamente no que se refere ao incentivo e promoção da inovação nas micro e pequenas empresas, destaque-se o SEBRAE e SEBRAE-SP, instituições privada sem fins lucrativos; $\mathrm{CNPq}$, fundação pública responsável pela promoção da ciência, tecnologia e inovação no Brasil e as próprias micro e pequenas empresas. Esses atores do SNI, importantes objetos de estudo desse artigo, são estudados em profundidade a seguir.

\subsection{Serviço Nacional de Apoio as Micro e Pequenas Empresas - SEBRAE}

Em 17 de julho de 1972, por iniciativa do Banco Nacional de Desenvolvimento Econômico (BNDE) e do Ministério do Planejamento, foi criado o Centro Brasileiro de Assistência Gerencial à Pequena Empresa (CEBRAE) para estimular o empreendedorismo e possibilitar a competitividade e a sustentabilidade dos empreendimentos de micro e pequeno porte. O Conselho Deliberativo do CEBRAE contava com a FINEP, a Associação dos Bancos de Desenvolvimento (ABDE) e o próprio BNDE. O início dos trabalhos se deu com o credenciamento de entidades parceiras nos estados. (SEBRAE, 2014)

Nos governos Sarney (1985-1990) e Collor (1990-1992), o CEBRAE enfrentou uma série de crises que o enfraqueceu como instituição. Neste período, sua vinculação passou do Ministério do Planejamento para o Ministério da Indústria e Comércio (MDIC). Com grande instabilidade orçamentária, muitos técnicos deixaram a instituição. Em 1990, foram demitidos 110 profissionais, o que correspondia a 40\% do seu pessoal (SEBRAE, 2014).

Em nove de outubro de 1990, o CEBRAE foi transformado em SEBRAE pelo decreto ${ }^{\circ}$ 99.570, que complementa a Lei ${ }^{\circ}$ 8029, de 12 de abril. A entidade desvinculou-se da administração pública e transformou-se em uma instituição privada, sem fins lucrativos e de utilidade pública, mantida por repasses das maiores empresas do país, proporcionais ao valor de suas folhas de pagamento (SEBRAE, 2014).

Para garantir o atendimento aos pequenos negócios, o SEBRAE atua em todo o território nacional. Além da sede nacional, em Brasília, a instituição conta com pontos de atendimento nas 27 unidades da Federação, onde conta com uma rede de quase 700 postos de atendimento presencial em todo o Brasil. O SEBRAE Nacional é responsável pelo direcionamento estratégico do sistema, definindo diretrizes e 
prioridades de atuação. As unidades estaduais desenvolvem ações de acordo com a realidade regional e as diretrizes nacionais.

\subsubsection{Finalidade}

A atuação do SEBRAE compreende educação empreendedora, a capacitação dos empreendedores e empresários, bem como articulação de políticas públicas que fomentem e facilitem o ambiente empreendedor, propiciar o acesso a novos mercados, tecnologia e inovação, incentivar a formalização das micro e pequenas empresas. Quanto à burocracia para a abertura e para o encerramento das empresas, o SEBRAE tem atuado junto aos órgãos responsáveis no sentido de minimizá-las.

O SEBRAE tem como vertente de trabalho o atendimento individual ou coletivo dos pequenos negócios nos segmentos da indústria, comércio, serviços e agropecuária onde apresenta as seguintes soluções: a) Informação - pesquisas, artigos, publicações e notícias; b) Consultoria Trata-se da disponibilização de um consultor que analisará sistematicamente a micro ou pequena empresa e poderá apresentar soluções no sentido de implantação e alinhamento de novas sistemáticas dentro da empresa visando o sistema, as pessoas ou os processos com vistas à busca de melhores resultados; c) Cursos oferecimento de mais de 40 cursos e palestras, presenciais e a distância, para atender quem já tem e quer ampliar seu negócio ou quem pensa em abrir a sua própria empresa. São cursos feitos sob medida para quem quer aprender desde as noções básicas de empreendedorismo até a gestão do próprio negócio; d) Premiações - reconhecimento e divulgação a sua visão empreendedora para todo o país por meio de premiações que valorizam, incentivam e estimulam os pequenos negócios a crescer (SEBRAE, 2014).

\subsubsection{Direcionamento Estratégico}

De acordo com o SEBRAE (2014b) seu Direcionamento Estratégico 2009-2015, aprovado pelo Conselho Deliberativo Nacional, a instituição procura adequar-se às novas exigências dos cenários socioeconômicos, onde se se destacam as seguintes atuações:

- Promover a inovação: incentivar a cultura de inovação nas micro e pequenas empresas, buscando a ampliação dos seus canais de acesso à inovação, e desenvolvendo diretamente e por meio de parceiros, novos modelos de negócios, de gestão, de processos e produtos para serem incorporados às MPEs, ampliando a sua competitividade empresarial;

- Fortalecer a cooperação entre as micro e pequenas empresas: promover a cultura da cooperação e o desenvolvimento de redes empresariais e institucionais, nacionais e internacionais, com ênfase no fortalecimento de parcerias efetivas e na formação de lideranças;

- Potencializar a conquista e a ampliação de mercados: Apoio a manutenção e a conquista de mercados, nacionais e internacionais;

- Orientar e capacitar em gestão, tecnologia e processos: reforçar a importância da gestão ao oferecer produtos e serviços de excelência, presencial e a distância, que atendam às necessidades das MPE e dos empreendedores, para que possam alcançar padrões mundiais de competitividade. 


\subsection{Conselho Nacional de Desenvolvimento Científico e Tecnologico - CNPq}

A partir da $2^{\mathrm{a}}$ Guerra Mundial, os avanços da tecnologia bélica, aérea, farmacêutica e energia nuclear despertaram os países para a importância da pesquisa científica. Em 1949 que o então Presidente Eurico Gaspar Dutra nomeou uma comissão especial para apresentar o anteprojeto de lei sobre a criação do Conselho de Pesquisas. A Reunião da Comissão para elaborar o projeto resultou na lei de criação do CNPq, em Abril de 1949. Depois de debates em diversas comissões, em 15 de janeiro de 1951, o Presidente Dutra sanciona a Lei de criação do Conselho Nacional de Pesquisas (CNPq, 2014).

A lei de criação do Conselho estabelecia como suas finalidades promover e estimular o desenvolvimento da investigação científica e tecnológica, mediante a concessão de recursos para pesquisa, formação de pesquisadores e técnicos, cooperação com as universidades brasileiras e intercâmbio com instituições estrangeiras. Hoje o CNPq, vinculado ao MCTI, trata-se de uma fundação pública, onde sua missão é:

Fomentar a Ciência, Tecnologia e Inovação e atuar na formulação de suas políticas, contribuindo para o avanço das fronteiras do conhecimento, o desenvolvimento sustentável e a soberania nacional" e como visão "Ser uma instituição de reconhecida excelência na promoção da Ciência, da Tecnologia e da Inovação como elementos centrais do pleno desenvolvimento da nação brasileira (CNPq, 2014b).

\subsubsection{Finalidade}

O Regimento Interno do CNPq (Portaria $n^{\circ}$ 816, de 17 de dezembro de 2002) institui como finalidades desta fundação a promoção e o fomento do desenvolvimento científico e tecnológico do país, bem como a contribuição na formulação das políticas nacionais de ciência e tecnologia. O Relatório de Gestão Institucional do CNPq (2009, p. 3) elenca suas atribuições, a saber:

Financiar tanto a formação, capacitação e aprimoramento de recursos humanos, no país e no exterior, quanto o fomento à pesquisa científica, tecnológica e de inovação, mediante o aporte de recursos orçamentário- financeiros para despesas de capital e de custeio de projetos, utilizando-se de recursos próprios, alocados ao seu orçamento, ou em parceria com outras instituições nacionais, de abrangência federal, estadual e regional, e internacional, por meio de transferências recebidas e/ou repassadas, mediante convênios e parcerias estabelecidas para essas finalidades.

O financiamento de formação, capacitação e aprimoramento de pessoas e grupos, seja no país ou no exterior, bem como o custeio de projetos tem sua importância revelada pelo fato proporcionar aos brasileiros desenvolvimento profissional com capacitação, possibilitando constantemente o contato com novas realidades. Questões de relevância técnica, econômica e social é objeto de pesquisa cientifica por parte dos bolsistas e grupos de pesquisa, contribuindo, sobremaneira, para o desenvolvimento do país e seu crescimento econômico e social, possibilitando, assim, maiores condições de competitividade. 


\title{
3.5 As Micro e Pequenas Empresas no Brasil
}

Segundo Franco (1991, p. 14) "empresa é toda atividade econômica com fins lucrativos, assim toda entidade que se constitui, sob qualquer forma jurídica, para exploração de atividade econômica, seja ela mercantil, industrial, comercial e prestação de serviço".

A definição da empresa pelo porte exerce um importante papel para o estabelecimento de políticas públicas, determinado os limites pelos quais as empresas podem se habilitar em usufruir determinados incentivos fiscais. Significa a possibilidade de acesso a uma série de incentivos: tributação, crédito exportação e simplificação burocrática que buscam alcançar objetivos econômicos sociais como: geração de emprego e renda, aumento das exportações, justiça fiscal e formalização.

Conforme disposto na Medida Provisória 275/05, cujos valores foram atualizados pelo Projeto de Lei da Câmara (PLC) 77/11 que ajusta a Lei Geral da MPE's (LEI COMPLEMENTAR 123/06), empresa de pequeno porte aquelas que possuem receita bruta anual de até $\mathrm{R} \$ 3,6$ milhões.

Cher (1990) observa que as micro e pequenas empresas tem papel fundamental na evolução da sociedade, contribuindo tanto do ponto de vista econômico, social e político. As micro e pequenas empresas apresentam melhor desempenho em atividades que demandam habilidades ou serviços especializados e rápida reação de acordo com a evolução das condições do ambiente, pelo fato de estarem concentradas próximas aos seus mercados.

Além disso, D. Oliveira (2004) afirma que as MPEs possuem características próprias: contribuição na geração do produto interno bruto, absorção de mão de obra, geração de renda, flexibilização de localização e composição do capital predominantemente nacional.

Figueiredo (2013, p. 1) assevera:

\begin{abstract}
Apesar de certa inexpressividade quando analisadas em separado, as micro e pequenas empresas representam uma força econômica considerável quando se ponderam dados como a participação no produto interno bruto (PIB) dos países e a parcela de empregos por elas gerados. Dificilmente o quadro seria outro, tendo em vista que estas empresas consistem na absoluta maioria do setor empresarial em diversos países. No Brasil, nos Estados Unidos e na região transfronteiriça da União Européia, os pequenos negócios compõem mais de $90 \%$ das empresas.
\end{abstract}

Porém, para o Instituto Brasileiro de Geografia e Estatística (2003), as MPEs se caracterizam por: baixa capitalização, altas taxas de natalidade e de mortalidade, forte presença de proprietários e/ou sócios nos negócios, centralização de poder, confusão entre pessoa física e jurídica, registros contábeis pouco adequados, contratação direta de mão de obra, utilização de mão de obra não qualificada ou pouco qualificada, baixo investimento em inovação e dificuldade de acesso a crédito.

Para Solomon (1986), a escassez de recursos cria obstáculos para o pequeno empresário desde o inicio de suas atividades, impedindo que o mesmo realize investimentos necessários em maquinário e tecnologia, de maneira a elevar sua produtividade e lucratividade. Essa dificuldade resulta em empresas com custos e despesas elevados, que operam com baixas margens e, conseqüentemente, ineficientes em termos operacionais.

\subsection{As Micro e Pequenas Empresas e a Inovação}

Para Pereira e Dathein (2012) a empresa caracteriza-se como a agente central da inovação, desempenhando papel fundamental na dinâmica econômica capitalista. 
A empresa é uma instituição dotada de capacidade de acumulação de conhecimento (PENROSE, 2006), o qual vem sendo tratado como o principal insumo produtivo, responsável pelas constantes inovações. Por sua vez, em grande medida as inovações têm sido resultado da trajetória evolutiva empresarial, que é condicionada pelo processo de aprendizado desenvolvido nos ambientes interno e interativo em que a empresa atua.

O tema da inovação por parte de pequenas empresas ganhou relevância nas últimas décadas, motivado por recentes desenvolvimentos teóricos, em especial, no enfoque neo-schumpeteriano que mostraram a partir de pesquisas empíricas, uma teia de relações estabelecidas pelas empresas que influenciam significativamente as atividades produtivas em geral, e as inovativas em particular. Relações com clientes e fornecedores, com empresas concorrentes e com institutos de pesquisa e/ou universidades, figuraram nas pesquisas como as mais importantes (ALBUQUERQUE, 1998).

Documento da Organization For Economic Co operation Development (1995) sobre a relação entre tecnologia e competitividade em pequenas empresas ressalta que, em geral, as PEs inovadoras apresentam: $i$ ) um gerente/proprietário qualificado em assuntos técnicos relacionados à especialização da empresa ou, ii) pessoal empregado com altos níveis de qualificação formal.

A literatura que trata desse tema destaca algumas hipóteses para a explicação da vantagem competitiva das micro e pequenas empresas na inovação em alguns setores industriais: fontes de geração de conhecimento, flexibilidade organizacional, menos níveis hierárquicos e de estruturas menos burocratizadas facilitam a tomada de decisões e as alterações no processo produtivo, constituindo importantes elementos a favorecer a atividade de inovação (OECD, 1993).

A presença de MPEs inovadoras na estrutura industrial está relacionada com os seguintes fatores (UTTERBACK, 1994): existência de atividades próprias de pesquisa e desenvolvimento; presença de mão-de-obra qualificada e flexibilidade hierárquica.

Nesse sentido, de acordo com Freeman (1995) as MPES atuam como um "elo" entre geração, uso e disseminação de inovações e o desenvolvimento econômico, desempenham simultaneamente o papel de agentes da inovação e instituições de aprendizado (NELSON, 2006).

\subsection{Programa Agentes Locais de Inovação - ALI}

O ALI, elaborado e executado pelo CNPq juntamente com o SEBRAE visa oferecer aos pequenos empresários a oportunidade de tornar-se mais competitivo junto ao mercado do seu segmento de atuação. A didática dessa difusão de informações está de acordo com as peculiaridades de cada negócio, com a intenção de gerar impacto interno na gestão empresarial e impactos externos nos mercados, concorrentes e clientes.

A forma que o SEBRAE em parceria com o CNPq se utilizam para promover a inovação nas empresas é por intermédio dos Agentes Locais de Inovação. Profissionais recém-formados, com os prérequisitos necessários para prestar acompanhamento especializado em concordância com o empresário.

O programa ALI vem ao encontro dos desafios industriais do país ameaçado pela concorrência internacional e de empresas brasileiras que se apoiam em produtos de baixo valor agregado e que possuem alto potencial de inovação para produtos e serviços.

Logo, em curto prazo, tem como objetivo promover a inovação e a aproximação das empresas com os provedores de solução através de um atendimento ativo, gratuito, continuado e com foco setorial e em longo prazo, contribuir a mudança do patamar das empresas pela inovação e diferenciação de produtos e serviços e consequentemente alcançar a inserção e reconhecimento dos produtos e serviços brasileiros nos principais mercados internacionais. 
O Programa ALI é dividido em seis etapas, que são:

1. Sensibilização de empresários: para a adesão, esta parte é composta pela sensibilização através de palestras, captação e seleção das empresas;

2. Adesão da empresa ao Projeto ALI: as empresas se comprometem a fazer parte do projeto assinando um Termo de Adesão, com a finalidade de se comprometerem a implantarem as futuras ações propostas pelos agentes;

3. Diagnóstico empresarial: quando o agente aplica o questionário na empresa que busca informações com o objetivo de identificar oportunidades de melhorias que viabilizem a inovação nas empresas;

4. Medir grau de inovação: com base no diagnóstico e na aplicação do questionário que identifica o grau de inovação da empresa;

5. Plano de ação: apresentação do plano de trabalho com as sugestões diversas e ações para a melhoria da empresa;

6. Implantação das Ações: Caso seja necessário, pode ser convidado um provedor de soluções, sendo este acompanhado pelo Agente Local de Inovação.

\subsubsection{Parceria SEBRAE/CNPq para o fomento da inovacão nas pequenas empresas}

A iniciativa tem como objetivo mapear o nível de competitividade das empresas e orientá-las gratuitamente para se manterem ativas no mercado, visando permitir que os setores sejam atendidos por agentes que desenvolveram bom nível de conhecimento na sua área de atuação. As principais atribuições dos Agentes Locais de Inovação referem-se à realização de visitas e à construção de diagnósticos com informações que possam subsidiar o atendimento às empresas, articulando vários interlocutores relacionados aos segmentos empresariais atendidos por cada agente, elaborando, em seguida, um plano de trabalho específico, que possa significar a adoção processual de ações inovadoras, relacionadas a âmbitos diversos na empresa.

Durante a participação no programa, as empresas recebem a visita do agente, que faz um diagnóstico da gestão da inovação, metodologia desenvolvida pelo SEBRAE em parceria com a Bachmann Associados LTDA, focada no rastreamento de tendências aplicadas pela organização para a criação de produtos, processos e/ou serviços inovadores.

Essa metodologia baseia-se nas mudanças ocorridas na empresa nos últimos três anos contempla treze diferentes dimensões: oferta, plataforma, marca clientes, soluções, relacionamento, agregação de valor, processos, organização, cadeia de fornecimento, presença, rede e ambiência inovadora. Ao aplicála, o agente tem a opção de adotar três escores diferentes: um (quando a inovação não está presente), três (quando a inovação é incipiente) ou cinco (quando a inovação está presente), sendo possível adotar apenas um escore por questão. A empresa que obtive conceito cinco em todas as dimensões beira a perfeição quanto à prática da inovação, conceito três em todas as dimensões, é considerada uma empresa inovadora, porém ainda com pontos de melhora e o conceito $01 \mathrm{em}$ todas as dimensões não possui preocupação identificada com a inovação.

A partir desse ponto, a empresa passa a ser acompanhada durante dois anos, período em que receberá orientações para a aplicação de ideias inovadoras, através também da aproximação com provedores de soluções, como institutos de pesquisas, centros tecnológicos e universidades. É feito paralelamente um levantamento da gestão empresarial, utilizando-se do questionário desenvolvido pela Fundação Nacional da Qualidade (FNQ), com base no Modelo de Excelência da Gestão (MEG). 
De acordo com o FNQ (2013), o diagnóstico empresarial esta baseado em 13 fundamentos de oito critérios. São os fundamentos: pensamento sistêmico; atuação em rede; aprendizado organizacional; inovação; agilidade; liderança transformadora; olhar para o futuro; conhecimento sobre clientes e mercados; responsabilidade social; valorização das pessoas e da cultura; decisões fundamentadas; orientação por processos; geração de valor, sendo os critérios: liderança; estratégias e planos; clientes; sociedade; informações e conhecimento; pessoas; processos e resultados.

Junto às micro e pequenas empresas, o programa ALI contribui para o aumento da competitividade, atuando de acordo com as características de cada empreendimento na definição das melhores opções de implementação de inovações e tecnologias. As mudanças geram impacto direto na gestão empresarial, na melhoria dos produtos e processos e na identificação de novos nichos de mercado para os seus produtos. Esse crescimento é associado à capacidade competitiva da empresa beneficiando, inclusive, a comunidade da qual faz parte e tendo um foco na dimensão social e ambiental da sustentabilidade.

A promoção do desenvolvimento local sustentável e a busca de uma maior competitividade das micro e pequenas empresas é o fundamento do Programa ALI, que tem obtido, por meio da atuação destes agentes em todo o território nacional, grande capilaridade no insumo da inovação, aproximando dois segmentos que muito têm a ganhar com tal relação: de um lado, micro e pequenas empresas que enfrentam muitas dificuldades na implementação de processos e programas inovadores e do outro, provedores de solução cientifico tecnológico, como universidades, centros de pesquisa e desenvolvimento, instituições de ensino e pesquisa, organizações certificadoras, parques tecnológicos e incubadoras.

A modalidade de contratação dos Agentes Locais de Inovação pelo CNPq se da através da bolsa de Fomento Tecnológico e Extensão Inovadora, que é voltada para a formação e a capacitação de recursos humanos no país, contribuindo "para a execução de projetos de pesquisa ou de desenvolvimento tecnológico, assim como atividades de extensão inovadora e transferência de tecnologia" (cf. RN015/2010, CNPq). A própria finalidade desta modalidade de bolsa aponta para a necessidade de fomento a ações que estejam vinculadas ao "desenvolvimento de produtos e processos inovadores" e à "disseminação de conhecimento" (idem), com importância acentuada por seu caráter relacionado à inclusão social e ao desenvolvimento econômico do país.

Busca-se, assim, uma otimização dos processos internos de cada empresa ou setor, de maneira particularizada, englobando desde as compras e a gestão dos recursos até o atendimento e as vendas, a produção e a distribuição, a partir do estudo sobre a capacidade de inovação de cada empresa ou setor.

$\mathrm{Na}$ medida em que os agentes locais de inovação iniciam seus trabalhos com o levantamento sistematizado de dados sobre a empresa ou o segmento de atuação que está atendendo, estas informações levantadas possibilitam tanto a tomada de conhecimento quanto um planejamento direcionado que traduzirá novas alternativas de crescimento. O conhecimento sistematizado é, assim, a base de formulação para planos de inovação comprometidos com a realidade local.

Ao final de 2013 o Programa ALI está em todos os 26 estados no Brasil e o distrito federal, com a distribuição de mais de 1100 agentes de inovação em locais com ampla cobertura geográfica, resultando numa ação sem precedentes em termos de alcance e capilaridade. Estes profissionais têm levado outros programas desenvolvidos pelo SEBRAE, como o SEBRAETEC e o SEBRAE MAIS, ao universo dos pequenos empreendimentos. O trabalho terá reforço de 780 milhões de reais de 2014 até 2016.

A implementação não é, contudo, uniforme, havendo grandes diferenças de estágios ao longo do território nacional. Nos escritórios regionais do SEBRAE em que o Projeto ALI já existia, estão em processo ações de ampliação e adequações relacionadas à expansão de seu alcance, a partir do aumento do número de agentes, de localidades e de empresas atendidas, oriundos do incremento do CNPq. Por outro 
lado, algumas regiões e escritórios locais do SEBRAE passaram a fazer parte do Projeto ALI apenas a partir da ampliação possibilitada por tal incremento. Esta situação demonstra que as articulações interinstitucionais no Brasil são de fundamental importância para a garantia de ações que possibilitem o fortalecimento da inovação e do desenvolvimento.

Além do aspecto pratico, os Agentes Locais de Inovação, dentro de suas atribuições realizam a confecção de dois artigos científicos com o foco nos resultados compreendidos no trabalho de campo. Trata-se de uma metodologia importante tendo em vista a escassez de material bibliográfico com o tema empreendedorismo e inovação nas micro e pequenas empresas, facilitando assim o acesso à pesquisa $\mathrm{e}$ discussão do tema.

\section{DISCUSSÃO}

Dado a avanço do processo de globalização dos mercados e o acirramento da concorrência em esfera mundial, vantagens competitivas, seja empresarial quanto nacional, se dão e dar-se-ão, cada vez mais com base na inovação, seja em produto, processo, mercado e organizacional.

Porém, ante a industrialização tardia brasileira, como afirma Daninho (2004) realizada, sobretudo pelo estado, a partir de projetos nacionais desenvolvimentistas; crises econômicas; elevadas taxas de juros; incipiência política; falta de acesso a linhas de financiamento e reservas de mercado, consequência de praticas protecionistas e mercado, as empresas brasileiras não desenvolveram estratégias competitivas, no transcorrer do século XX, com base em inovação, como foi realizada pelas empresas nos países ocidentais.

Além disso, dado a importância econômica e social das micro e pequenas empresas no Brasil, conforme foi exposto por D. Oliveira (2004) contribuição para o crescimento do produto interno bruto, captação de mão de obra, geração de renda, flexibilização de localização de mercado e composição do capital social das empresas maciçamente nacional, como também no processo de inovação, como afirma Utterback (1994) devido a atividades de pesquisa e desenvolvimento; mão-de-obra qualificada e flexibilidade na estrutura organizacional. Dada essas capacidades, Freeman (1995) conclui que as MPES atuam como um "elo" entre geração, uso e disseminação de inovações e o desenvolvimento econômico.

Os expostos supracitados pelos três autores consagrados entram em consonância com os objetivos do programa Agentes Locais de Inovação, dada ao mesmo tempo a fragilidade e a importância das micro e pequenas empresas para o Brasil e a inovação como ferramenta sustentável para geração de vantagens competitivas.

Logo, sendo o pressuposto fundamental do ALI a aproximação das empresas com os provedores de solução (Instituto de Pesquisas Tecnológicas, Associação Brasileira de Normas Técnicas, Serviço Nacional de Aprendizado Industrial, Financiadora de Estudos e Projetos, Banco Nacional de Desenvolvimento Econômico e Social, Universidade de São Paulo e etc.) através de com foco setorial e em longo prazo, contribuir a mudança do patamar das empresas pela inovação e diferenciação de produtos e serviços e consequente inserção e reconhecimento dos produtos e serviços brasileiros nos principais mercados internacionais.

Ao mesmo tempo, contribuir para o fortalecimento e integração no Sistema Nacional de Inovação brasileiro, indo ao encontro dos objetivos apontados pela Estratégia Nacional de Ciência, Tecnologia e Inovação do Ministério da Ciência, Tecnologia e Inovação (2012) no que se refere à consolidação da inovação empresarial com pressuposto de aumento da competitividade industrial, principalmente no que se refere à produtividade, geração de emprego e da melhoria da qualidade de vida. Consequentemente colaborando para a transição de um modelo de desenvolvimento econômico de eficiência para a inovação, 
em consonância com Braun (2006) e Pacheco e Corder (2011), no qual permita às empresas e ao complexo científico-tecnológico aproveitar as oportunidades de inovação.

Como também no combate aos problemas apontados por Albuquerque (1998), que define o SNI brasileiro como notadamente frágil e incipiente devido: a desarticulação entre as políticas de cientificas e tecnológicas com políticas econômicas e sociais; cortes de investimento em pesquisa e desenvolvimento, como também na ciência básica; industrialização atrelada ao capital externo; dependência da tecnologia estrangeira e, sobretudo a falta de articulação entre os atores entre o setor público e o privado.

Além disso, o Programa ALI coloca a empresa como agente central no processo de inovação, em consonância com Pensore (2006) e Pereira e Dathein (2012) que afirmam que as empresa caracteriza-se como a agente central dinâmica econômica capitalista, dotada de capacidade de acumulação de conhecimento tácito, principal ferramenta da inovação.

Portanto, o Programa Agentes Locais de Inovação, realizado por importantes atores do Sistema Nacional de Inovação brasileiro, SEBRAE e CNPq, e no estado de São Paulo em parceria com SEBRAE SP, vai ao encontro tanto da teoria Schumpteriana onde as empresas são os principais agentes no processo de inovação, quanto da teoria Neo Schumperiana no que se refere à articulação entre as instituições componentes do SNI. Além disso, o ALI:

Materialização da transição de uma política de ciência e tecnologia para uma efetiva política de inovação, tendo como protagonista a pequena empresa:

- Auxilia no processo de construção de uma cultura organizacional voltada para inovação junto às pequenas empresas e outras instituições do Sistema Nacional de Inovação brasileiro;

- Contribui para maior eficácia e eficiência dos estímulos das políticas públicas de inovação voltadas para as pequenas empresas,

- Contribui para edificação e consolidação de vantagem competitiva empresarial através de estratégias de inovação;

- Articula a integração das pequenas empresas com outras organizações do Sistema Nacional de Inovação;

- Contribui com o desenvolvimento e maturação do Sistema Nacional de Inovação do país;

- Em longo prazo, alterar a estrutura produtiva no país, tendo como base de seu desenvolvimento econômico e social, a inovação e o empreendedorismo.

-

O programa ALI vai tanto ao encontro do direcionamento estratégico do Sistema SEBRAE 20092015 no que se refere à promoção da inovação e ao fortalecimento da cooperação nas pequenas empresas, quanto do CNPq no que se refere a sua missão em fomentar a inovação e atuar na formulação de suas políticas, contribuindo para o desenvolvimento sustentável do país.

\section{CONCLUSÃO}

Com o acirramento da competitividade entre empresas e nações no inicio do século XXI, decorrente do processo de globalização, a inovação tornou-se uma ferramenta estratégica para promoção e sustentação do desenvolvimento econômico em longo prazo. A inovação apresenta uma relação direta com o aumento das exportações, ritmo de crescimento das empresas, melhora do valor agregado da produção nacional e a estrutura salarial do país, tendo na empresa o agente principal destas transformações. A dinâmica empresarial é fundamental para o desenvolvimento de novas tecnologias em produtos, processos 
e abertura de novos mercados na medida em que são consideradas instituições de produção, de negócios e de aprendizado.

A inovação nas micro e pequenas empresas ganhou destaque devido ao desenvolvimento teórico Neo Schumpeteriano que correlaciona produtividade e inovação, logo é fundamental o fomento da inovação nas MPEs na medida em que contribuem na geração do produto interno bruto, absorção de mão de obra, geração de renda, flexibilização de localização e composição do capital predominantemente nacional.

Porém, grande parte das MPEs, se caracterizam por: baixa capitalização, altas taxas de natalidade e de mortalidade, forte presença de proprietários e/ou sócios nos negócios, centralização de poder, confusão entre pessoa física e jurídica, registros contábeis pouco adequados, contratação direta de mão de obra, utilização de mão de obra não qualificada ou pouco qualificada, baixo investimento em inovação e dificuldade de acesso a créditos.

A teoria Neo Schumpeteriana avança na compreensão do fenômeno da inovação e do desenvolvimento econômico e empresarial, onde contribuem para a construção de um marco referencial essencial à concepção de políticas publicas de ciência e tecnologia com foco na inovação, o qual se articula em torno do conceito de Sistema Nacional de Inovação, base fundamental para a criação de vantagem competitiva de nações e empresas.

O SNI depende de um relacionamento articulado empresas e suas redes de cooperação e interação; universidades e institutos de pesquisa; instituições de ensino; sistema financeiro; sistemas legais e instituições de coordenação, esse inter-relacionamento deve ser fomentado por uma política nacional de ciência, tecnologia e inovação em consonância com a política de desenvolvimento econômico e industrial.

A construção de uma política de inovação é um requisito necessário para a criação das bases do desenvolvimento brasileiro, porém, pode se verificar que o modelo de desenvolvimento industrial e econômico brasileiro desde a $2^{\text {a }}$ Guerra Mundial até o fim da primeira década do século XXI foi marcado por três fases distintas: primeira fase pelo desenvolvimento por intermédio do crescimento, ou seja, pela industrialização extensiva; a segunda fase pelo neoliberalismo, como a forma de promover o desenvolvimento econômico e competitivo do país e por fim, a terceira fase, de revalorização das políticas públicas como instrumento fundamental para o desenvolvimento, onde a inovação começa a assumir importância paulatina no discurso da política de ciência, tecnologia e desenvolvimento. No transcorrer desse processo de desenvolvimento econômico industrial brasileiro, a inovação somente começou, ainda de maneira tímida, a fazer parte da política de desenvolvimento nacional somente no inicio do século XXI e ainda com complexo cientifico tecnológico como protagonista no processo inovativo.

Além disso, no que se refere ao Sistema Nacional de Inovação brasileiro, a falta de sinergia e articulação entre as organizações empresariais, governamentais, universidades, institutos de pesquisa e é dos maiores desafios à consolidação de um sistema de inovação no Brasil. Os desafios do país no campo da inovação não são poucos e estão relacionados à governança das políticas públicas, a relação entre PD\&I, empreendedorismo, globalização e formação de recursos humanos.

Igualmente, as próprias empresas brasileiras têm, de uma maneira geral, familiaridade reduzida com a inovação. Esse fato compromete a eficácia e a eficiência dos estímulos da política de inovação, assim como a capacidade dessas próprias empresas edificarem vantagem competitiva através de estratégias de inovação. Essa limitação decorre da história do desenvolvimento das empresas brasileiras, no transcorrer do processo de industrialização do país, de sua estrutura e das condições do ambiente macroeconômico nacional.

Tanto a política, quanto as estratégias de entidades empresariais nacionais precisam estar orientadas para a mudança das condições da estrutura produtiva brasileira de forma a torná-la mais 
favorável à inovação. Em outras palavras, o grande desafio brasileiro atual é o de conseguir transformar a política de C\&T em uma efetiva política de inovação e fazer dessa a base da nova política de desenvolvimento, colocando a empresa como protagonista no processo de inovação e ao mesmo tempo articular e integrar as instituições do Sistema Nacional de Inovação.

Nesse sentido o Sistema SEBRAE, juntamente com o CNPq, através do programa Agentes Locais de Inovação vem ao encontro tanto da necessidade de integração das empresas, principais atoras no processo de inovação, juntamente com provedoras de soluções de notório saber no Brasil: USP, Instituto de Pesquisas Tecnológicas, BNDES, FINEP, incubadoras e agencias de fomento a inovação, se consolidando com um braço de política de C\&T, em outras palavras, uma nova política de desenvolvimento, podendo contribuir fundamentalmente para a maturação e desenvolvimento do Sistema Nacional de Inovação brasileiro através da integração entre as políticas públicas de apoio à competitividade empresarial, ações e programas especificamente focados em ciência, tecnologia e Inovação para as micro e pequenas empresas e a realização de esforços institucionais de promoção da inovação empreendidos no setor privado brasileiro.

Em suma, as políticas públicas de acesso à inovação devem protagonizar a empresa e a partir do conceito de Sistemas Nacionais de Inovação pensá-las de forma integrada e coesa com outras organizações pertencentes ao SNI. A debilidade das empresas em inovação e a imaturidade do SNI brasileiro constituem-se um dos maiores entraves ao processo de superação do subdesenvolvimento e de sua condição periférica na divisão internacional de trabalho. Através de políticas públicas como Agentes Locais de Inovação, o Brasil pode evoluir na divisão internacional de trabalho, de exportador de commodities para um país competitivo nos mercados internacionais, exportador de produtos, serviços e processos de alta densidade tecnológica e conhecimento científico.

\section{REFERENCIAS}

ALBUQUERQUE, E. M. Patentes segundo a abordagem neo-schumpeteriana: uma discussão introdutória. Revista de Economia Política, v.18, n.4, p. 65-83, 1998.

AVERCH, H. A. A Strategic Analysis of Science \& Technology Policy. Baltimore/London: The Johns Hopkins University Press, 1985.

BAPTISTA, M. A. C. A Abordagem Neo-Schumpeteriana: desdobramentos normativos e implicações para a política industrial. Tese de Doutorado, Universidade Estadual de Campinas, SP, Brasil, 1997.

BAGATtolli, C. Política cientifica e tecnológica no Brasil: mitos e modelos num país periférico. 2013. Tese de Doutorado em Política Científica e Tecnológica, Instituto de Geociências, Universidade Estadual de Campinas.

BRASIL. Lei Complementar n. 123/06, de 14 de dezembro de 2006. Institui o Estatuto Nacional da Microempresa e da Empresa de Pequeno Porte Diário Oficial da União, seção 1.

BRASIL. Ministério De Ciência, Tecnologia E Inovação. Estratégia Nacional de Ciência, Tecnologia e Inovação 2012-2015 e Balanço das Atividades Estruturantes. Brasília: 2012.

BRAUN, D. The mix of policy rationales in science and technology policy. Melbourne Journal of Politics, v.31, p. 8-35, 2006. 
BUENO, A. Utilização de dos mecanismos de apoio financeiro a inovação tecnológica por empresas de São Carlos. 2011. Dissertação de Mestrado em Engenharia de Produção, Centro de Ciências Exatas e Tecnologia, Universidade Federal de São Carlos.

CALMANOVICI, C. E. A inovação, a competitividade e a projeção mundial das empresas brasileiras. Revista USP, v. 1, n. 89, p. 190-203, 2011.

CASSIOLATO, J.E.; LASTRES, H.M.M. Inovação e sistemas de inovação: relevância para a área de saúde. Revista Eletrônica de Comunicação, Informação \& Inovação em Saúde, v.1, n.1, p. 153-162, 2007.

CASTELLS, M. A sociedade em rede. São Paulo: Paz e Terra, 1999.

CASTELLS, M. A Sociedade em Rede. São Paulo: Paz e Terra, 2002.

CHER, R. A gerência das pequenas e médias empresas. São Paulo: Maltese, 1990.

CNPq. Conselho Nacional De Desenvolvimento Científico E Tecnologico. Relatório de Gestão Institucional. 2009. Disponível em:

<http://www.cnpq.br/documents/10157/45694/relatorio_gestao_2009.pdf.> Acesso em: 02 fev. 2014.

CNPq. Conselho Nacional De Desenvolvimento Científico E Tecnologico.. A Criação. 2014. Disponível em: < http://www.cnpq.br/web/guest/a-criacao.> Acesso em: 02 fev. 2014.

CNPq. Conselho Nacional De Desenvolvimento Científico E Tecnologico. O CNPq. 2014. Disponível em: <http://www.cnpq.br/web/guest/o-cnpq;jsessionid=85657906D3D3B74C20320B0762F5F425.> Acesso em: 02 fev. 2014.

DAGNINO, R. P. A tecnologia social e seus desafios. In: Tecnologia social, uma estratégia para o desenvolvimento. Rio de Janeiro: Fundação Banco do Brasil, 2004.

DAGNINO, R. P. Um debate sobre a tecnociência: neutralidade da ciência e determinismo tecnológico. Campinas: Unicamp, 2007.

FIGUEIREDO, F. Pequenas empresas e regime diferenciado de contratação. 2013. Disponível em: < http://www.cedipre.fd.uc.pt.> Acesso em: 02 fev. 2014.

FRANCO, H. Contabilidade industrial. São Paulo: Atlas, 1991.

FREEMAN, C. The National System of Innovation in historical perspective. Cambridge Journal of Economics, v.19, n.1, p.5-24, 1995.

FNQ. FUNDO NACIONAL DA QUALIDADE. Modelo de Excelência de Gestão. 2013. Disponível em: $<$ http://www.fnq.org.br/avalie-se/metodologia-meg/modelo-de-excelencia-da-gestao.> Acesso em: 02 fev. 2014.

GADELHA, C.A.G. Política industrial: uma visão Neo-Schumpeteriana sistêmica e estrutural. Revista de Economia Política, v.21, n.4, p.149-71, 2001.

IBGE- INSTITUTO BRASILEIRO DE GEOGRAFIA E ESTATÍSTICA. As micro e pequenas empresas comerciais e de serviços no Brasil. Rio de Janeiro: Autor, 2003.

KALLERUD, E. Goal conflicts and goal alignment in science, technology and innovation policy discourse. In: EASST 2010 Conference: Practing Science and Technology, Performing the Social. Trento: EASST. 
MALERBA, F. Sectoral systems and innovation and technology policy. Revista Brasileira de Inovação. v.2, n.2, p. 329-375, 2003.

NELSON, R. R. As fontes do crescimento econômico. Campinas: UNICAMP, 2006. ORGANIZATION FOR ECONOMIC CO OPERATION DEVELOPMENT. Impacts of national technology programmes. Paris: 1995.

ORGANIZATION FOR ECONOMIC CO OPERATION DEVELOPMENT. Small and Medium-sized Enterprises: Technology and Competitiveness. Paris: 1993.

ORGANIZATION FOR ECONOMIC CO OPERATION DEVELOPMENT. The Oslo Manual: The Measurement of Scientific and Technical Activities. Paris: 1997.

OLIVEIRA, D. P. R. Planejamento estratégico: conceitos, metodologia e práticas. São Paulo: Atlas, 2004.

OLIVEIRA, M. B. Sobre a mercantilização da ciência: a dimensão programática. .2014. Disponível em: <http://paje.fe.usp.br/ mbarbosa/mc-dp.pdf.> Acesso em: 02 fev. 2014.

PACHECO, C. A.; CORDER, S. Mapeamento Institucional e de medidas de política com impacto sobre a inovação produtiva e a diversificação das exportações. Campinas: CEPAL, 2011.

PENROSE, E. A teoria do crescimento da firma. Campinas: UNICAMP, 2006.

PEREIRA, A. J.; DATHEIN, R. Processo de aprendizado, acumulação de conhecimento e sistemas de inovação. Revista Brasileira de Inovação, v.11, n.1, p.137-166, 2012.

PEREZ, C. Cambio tecnológico y oportunidades de desarrollo como blanco móvil. Revista de La CEPAL, v.1, n.75, p. 115-136, 2001.

POSSAS, M. Economia evolucionária neo-schumpeteriana: elementos para uma integração micromacrodinâmica. Estudos Avançados, v.22, n. 63, p. 281-305, 2008.

SAGASTINI, F. R. Tecnologia, planejamento e desenvolvimento autônomo. São Paulo: Perspectiva, 1986.

SAVIANI, D. O Plano de Desenvolvimento da Educação: análise do projeto do MEC. Educação \& Sociedade, v.28, n.100, p. 1231-1255, 2007.

SALERMO, M. S.; KUBOTA, L. C. Estado e Inovação. In: DE NEGRI, J. A.;KUBOTA, L. C. (Orgs.). Políticas de Incentivo à Inovação Tecnológica. (pp. 13-64). Brasília: IPEA, 2008.

SEBRAE- SERVIÇO BRASILEIRO DE APOIO AS MICRO E PEQUENAS EMPRESAS. Estratégia. 2014. Recuperado 20 de maio de 2014, de Disponível em:

$<\mathrm{http} / / \mathrm{hmg}$.sebrae.com.br/sites/PortalSebrae/canais_adicionais/conheca_estrategia. Acesso em: 20 maio 2014.

SEBRAE- SERVIÇO BRASILEIRO DE APOIO AS MICRO E PEQUENAS EMPRESAS. Quem Somos. 2014. Recuperado 20 de maio de 2014, de Disponível em: <http://www.sebrae.com.br/sites/PortalSebrae/canais_adicionais/conheca_quemsomos.> Acesso em: 20 maio 2014.

SEBRAE- SERVIÇO BRASILEIRO DE APOIO AS MICRO E PEQUENAS EMPRESAS. Taxa de Sobrevivência de Empresas no Brasil. 2013. Disponível em:

<http://bis.sebrae.com.br/GestorRepositorio/ARQUIVOS_CHRONUS/bds/bds.nsf/45465B1C66A6772D8 32579300051816C/\$File/NT00046582.pdf. .> Acesso em: 27 jun. 2014. 
SEBRAE- SERVIÇO BRASILEIRO DE APOIO AS MICRO E PEQUENAS EMPRESAS. Escola de Negócios. 2014. Disponível em: <http://www.sebraesp.com.br/index.php/239uncategorised/institucional/escola-de-negocios> Acesso em: 20 maio. 2014.

SEBRAE- SERVIÇO BRASILEIRO DE APOIO AS MICRO E PEQUENAS EMPRESAS. Equipe. 2014. Disponível em: <http://www.sebraesp.com.br/index.php/199-uncategorised/institucional/equipe> Acesso em: 20 fev. 2014.

SCHUMPETER, J. A. Capitalismo, socialismo e democracia. Rio de Janeiro Jorge Zahar, 1984.

SICSÚ, J.; CASTELAR, A. (Org.). Sociedade e Economia: estratégias de crescimento e desenvolvimento. Brasília: IPEA, 2009.

SOLOMON, S. A grande importância da pequena empresa: A pequena empresa nos Estados Unidos, no Brasil e no mundo. Rio de Janeiro: Editorial Nórdica, 1986.

TEIXEIRA, E. C. O Papel das políticas públicas no desenvolvimento local e na transformação da realidade. Salvador: UFBA, 2002.

UTTERBACK, J. M. Mastering the Dynamics of Innovation: How Companies Can Seize Opportunities in the Face of Technological Change. Cambridge: Harvard Business School Press, 1994.

VILHA, A. P. M. (2013). Características e Perspectivas das Interações para Inovação entre Universidades e Empresas no Brasil. Revista Economia \& Tecnologia, v.9, n.2, p. 126-134, 2013.

VIOTTI, E. B. Brasil: de política de C\&T para política de inovação? Evolução e desafios das políticas brasileiras de ciência, tecnologia e inovação. In: CGEE, Avaliação de políticas de ciência, tecnologia e inovação: Diálogo entre experiências internacionais e brasileiras (p. 137-173). Brasília: CGEE, 2008.

VILLASCHI, A. Anos 90 uma década perdida para o sistema nacional de inovação brasileiro? São Paulo em Perspectiva, v.19, n. 2, p. 3-20, 2005. 